MSCRA

3,2

78

Received 23 October 2020

Revised 19 January 2021

21 March 2021

Accepted 5 April 2021

\section{Blockchain-integrated technologies for solving supply chain challenges}

\author{
Dhruman Gohil and Shivangi Viral Thakker \\ Mechanical, KJ Somaiya College of Engineering, Mumbai, India
}

\begin{abstract}
Purpose - Blockchain technology was developed to synchronize the data and transactions over the supply chain network and connected nodes. This paper aims to show how blockchain technology can enhance flexibility and agility in supply chain operations. The integration of blockchain and other recently developed technology can help deal with supply chain uncertainties and other challenges being faced by the industry.

Design/methodology/approach - Through an extensive literature review of existing research papers and conversation with supply chain managers, barriers and challenges in the supply chain were identified. Some elements were researched of blockchain technology that can be used to resolve some challenges. Blockchain technology and other technologies integration is developed for implementation in supply chain for better visibility and efficiency of supply chain.
\end{abstract}

Findings - The challenges in the supply chain are categorized, and the solution is given through the integration of blockchain and other technologies like Internet of Things and artificial intelligence. The integration shows the execution of tasks through blockchain and various technologies in supply chain. Research limitations/implications - Blockchain in supply chain is finding its strong place in India when compared to developing nations. There is a need for technology experts, supply chain managers and consumers to understand blockchain's importance. Challenges faced by industries to use blockchain may be analyzed further with real-life industry case studies.

Practical implications - This research helps enterprises in successful execution of smart technologies in their supply chains. This research helps enterprises in successful execution of smart technologies in their supply chains. Managers and practitioners may use the models developed in real-time implementation. The technologies are described in detail to help the practitioners select the best suitable for their organization. Social implications - Digital supply chains are finding the way in industries due to lean and efficient nature. It is beneficial to use the smart technologies to make supply chain green and sustainable.

Originality/value - The implementation of the digital supply chain and its challenges are discussed in the research paper. This will work as a platform for research in the area of technologies for supply chain.

Keywords Smart contracts, Internet of things, Supply chain operations, Blockchain technology,

Artificial intelligence

Paper type Research paper

\section{Introduction}

The supply chain includes all the activity that involves production of goods and delivering finished goods from procurement stage to product stage. The supply chain in all industries contains very complex architecture and framework. All industries need to improve their supply chain to enhance productivity and gain more profits in business.

Maintaining a good supply chain has its challenges and barriers like trust among stakeholders, transparency and efficiency at each level of the supply chain. Blockchain has the potential to enhance flexibility and agility in supply chain operations (Cole et al., 2019).

(C) Dhruman Gohil and Shivangi Viral Thakker. Published in Modern Supply Chain Research and Applications. Published by Emerald Publishing Limited. This article is published under the Creative Commons Attribution (CC BY 4.0) license. Anyone may reproduce, distribute, translate and create derivative works of this article (for both commercial and non-commercial purposes), subject to full attribution to the original publication and authors. The full terms of this license may be seen at http:// creativecommons.org/licences/by/4.0/legalcode 
Blockchain allows all the stakeholder involved in the ecosystem to participate, share and validate upon all pieces of information and data. Blockchain can be presented append-only transactional data store, for centralized brokers that are handled by single trusted authorities (Viriyasitavat et al., 2019).

This paper examines challenges of conventional supply chain and classifies them according to a suitable technical solution. Application and implementation of modern technologies such as blockchain, artificial intelligence (AI) and Internet of Things (IOT) has many advantages for resolving difficulties. The paper presents theoretical work for finding supply chain challenges and coming up with possible solutions by implementing blockchain technology architecture and its integration with other recently developed technologies. The research considers all levels of supply chain, starting from raw materials of the product to the product lifecycle until it reaches the consumer. Some objectives of the research are as follows:

(1) Identifying challenges of traditional supply chain.

(2) Classifying the problems and determining the technology.

(3) Study the integration of blockchain with the technology to understand how it can be used to make the supply chain operations more efficient and agile.

(4) Development of integrated architecture implementing blockchain and other modern technologies individually to make complete process more transparent.

In this paper ahead, integration of blockchain and other integration of technology like IOT and AI with blockchain is discussed with a process flowchart. Some of the challenges of all supply chain members are carried out, and their solution is given through blockchain and integration of modern technologies, followed by a discussion and conclusion.

\section{Literature survey}

Walmart Canada has started with the implementation of blockchain technology with the logistics firms for inventory transportation. A shared node of a blockchain server allows to synchronize track shipments, logistics data and automate payments without requiring changes to the logistics firms' operations or information technology systems (Banerjee, 2015).

Maersk and IBM employ blockchain technology to digitize trade workflow and operations, create a global tamper-proof system and track shipments/deliveries end-to-end, including expensive point-to-point communications. Through blockchains, companies gain a real-time digital ledger of transactions and movements for all participants in their supply chain network.

IBM and Samsung took a step by IOT devices that consume electricity into blockchainbased energy management (Viriyasitavat et al., 2019). If all members of the supply chain use blockchain technology properly, it can be proved very profitable and stable to increase the security and transparency of supply chain.

\subsection{Blockchain technology}

Blockchain technology synchronizes transactions, contracts and data across all nodes and network, and each stakeholder validates transaction and verifies it (Abeyratne and Monfared, 2016). Blockchain is a distributed ledger that is visible and accessible to everyone include in the network. Blockchain technology is a chain of blocks, and every block contains thousands of verified transactions. Due to many blocks connected in one string, it becomes tough for someone to tamper the data. Blockchain technology allows creating a portable

Blockchainintegrated technologies 
MSCRA

3,2

80

identity. Many companies are heading their operations toward efficient digital supply chain (DSC) under required standards, solutions for integrating business processes with all the supply chain members in their network.

Blockchain gives us the technological capability of creating a record of human exchange, currency exchange and all kinds of physical assets. All types of assets can be stored, moved, transacted and managed connected to a distributed ledger connected to millions of computers. The distribution process of a blockchain system relies on consensus protocol, allowing mutually untrusted, uncoordinated parties to agree on transactions and blocks on blockchain server (Zheng et al., 2018).

All the supply chain members in industries are linked to the blockchain through a matrix of nodes. All the transactions and data of members in a chain are stored and managed at the same place (Vanpoucke et al., 2009). All members and stakeholders of the chain can easily interact with each other and get the trusted and correct data of all the transactions. Complete decentralization of all the members in the chain can be formed. It forces many potential users to re-engineer and streamline their systems, clean up their data, upgrade their databases and work across their network to create solutions for the common good. In the area of supply chains, once CPS (cyber-physical systems) autonomously decide to order for material usage and tracking information, replacement from suppliers can be stored in blockchain ledger, allowing resilient and accurate tracking information and preventing counterfeit products (Viriyasitavat et al., 2019).

2.1.1 Rationale. The major purpose of blockchain technology for supply chain is tracking all transactions of products and entire product life cycle. The tracking of processes and items from raw materials through suppliers to the customers with data, manufacturing, locations, etc. gives better transparency, increasing the efficiency and control on operations. There is strong need of converting traditional supply chain into digital supply chain to remove slow and manual processes, strengthening traceability and reducing IT transaction costs. All the medium-sized organization have enterprise resource planning (ERP) system as their management and planning system, but ERP can be used in internal organization; blockchain can help to connect all the organization of supply chain network on single server and connects all responsible members, stakeholders (Kim and Laskowski, 2018). Blockchain in supply chain allows all supply chain members to verify the requested data and then upload on the blockchain server so that data is not tampered by anyone. This helps all members to get trust over systems. Integration of modern disruptive technologies helps supply chain to achieve real-time insights of operations and provides secured way of mining, storing and analyzing data.

2.1.2 Advantages of blockchain in supply chain. All the stages in the supply chain use ERP software to store and manage day-to-day business activities such as handling employees, accounting, production, compliance, etc. individually. Blockchain technology helps to connect all the organizations in supply chain network and increase efficiency and traceability of the overall process (Stevenson and Spring, 2007). Blockchain and integration of other technology with blockchain enhance the product lifecycle management. It gives real-time feedback to the consumers and the other organization included in the supply chain. It can revolutionize the digital world by enabling a distributed consensus, where every online transaction involving digital assets, past and present, can be verified at any time in the future (Shireesh and Petrovsky, 2016). It does this without settlement of security privacy of the digital assets and contracts involved (Li et al., 2020). Whenever a transaction is processed between any of the parties in the supply chain, all the members get the real-time tracking of the operations and then validate it. Once validated, they get added to the public ledger of blockchain server, which cannot be tampered and hacked easily. The stakeholders and investors involved in the supply chain organizations can track the complete process, including finance, legal, operations, demand and supply forecasting and logistics providers (see Table 1). 


\begin{tabular}{|c|c|c|c|c|}
\hline $\begin{array}{l}\text { Sr } \\
\text { No } \\
\end{array}$ & Advantage & Description of advantage & Source & $\begin{array}{l}\text { Blockchain- } \\
\text { integrated }\end{array}$ \\
\hline 1 & $\begin{array}{l}\text { All the contracts and } \\
\text { transactions can be stored } \\
\text { digitally }\end{array}$ & $\begin{array}{l}\text { In a blockchain server, a transaction is recorded } \\
\text { on the server and the document gets it own } \\
\text { unique hash }\end{array}$ & $\begin{array}{l}\text { Abeyratne and } \\
\text { Monfared (2016) }\end{array}$ & \\
\hline 2 & $\begin{array}{l}\text { More visibility and } \\
\text { transparency }\end{array}$ & $\begin{array}{l}\text { As blockchain contains many secure nodes that } \\
\text { is accessible to all the members involved, all the } \\
\text { transactions and documents are completely } \\
\text { visible to members on real-time basis }\end{array}$ & Hu et al. (2019) & 81 \\
\hline 3 & $\begin{array}{l}\text { Trust among stakeholder } \\
\text { increases }\end{array}$ & $\begin{array}{l}\text { As there is complete transparency, blockchain } \\
\text { servers record all the transactions that cannot be } \\
\text { changed once updated on the server, trust } \\
\text { among stakeholder increases }\end{array}$ & Kshitri (2018) & \\
\hline 4 & $\begin{array}{l}\text { More accurate and reliable } \\
\text { data for analytics }\end{array}$ & $\begin{array}{l}\text { All entries in blockchain server are validated } \\
\text { through a public verification process that } \\
\text { ensures accuracy without the need for a central } \\
\text { authority. All the computers together verifies all } \\
\text { the entries before updating on the server as per } \\
\text { specified rules and controls that are already } \\
\text { embedded in system }\end{array}$ & Bi et al. (2013) & \\
\hline 5 & $\begin{array}{l}\text { Decreases any kind of } \\
\text { probability of fraud and } \\
\text { tampering in the process }\end{array}$ & $\begin{array}{l}\text { It is very difficult to perform fraud on blockchain } \\
\text { server and its transactions because of } 51 \% \\
\text { attack system. Each and every entry is stored } \\
\text { and updated on millions of nodes/computers } \\
\text { which makes impossible for hackers for } \\
\text { transaction reversal }\end{array}$ & $\begin{array}{l}\text { Wattana } \\
\text { Viriyasitavat et al. } \\
\text { (2019) }\end{array}$ & $\begin{array}{r}\text { Table } 1 . \\
\text { Advantages of } \\
\text { blockchain in } \\
\text { supply chain }\end{array}$ \\
\hline
\end{tabular}

The implications of blockchain technology in supply chain operations is not only limited to manufacturing companies but also in healthcare, retail, banks, fintech start-ups, media and entertainment, agriculture, law and most crucial government sectors. Blockchain's other functions that are used to make the supply chain operations more agile are inventory management, demand forecasting, asset tracking and intellectual property storage (Nawari and Ravindran, 2019). Real estate is the other example in which a large number of organizations or suppliers are involved. It becomes tough for the constructions companies to track the complete process and product lifecycle by all the suppliers and distributors. Blockchain and its integration with other technology can be proved very helpful in the real estate industry to form a complete decentralization (Wang et al., 2017).

2.1.3 Blockchain technologies and supply chain uncertainties. As the supply chain includes many stakeholders and organizations, it becomes difficult to make decisions. Because of the complex structure of the supply chain, there exist many uncertainties that need to be resolved to prevent damage in operations. Fuzzy logic can be used to measure the supply chain performance and reduce the uncertainties that exist in the supply chain. Fuzzy logic helps to get a deeper insight into process performance, operations from the input and output aspects than traditional accounting and measuring methods. $\mathrm{Xu}$ and Viriyasitavat (2019) have proposed a supply chain performance measurement system using AHP and fuzzy logic which was applied to integrate both qualitative and quantitative metrics to provide a complete view of the supply chain management and its overall competitiveness.

Some applications of fuzzy logic that can be applied in the supply chain involved route planning for logistics, equipment maintenance for manufacturers, the efficiency of automatic 
MSCRA

3,2

82

machines, quantitative pattern analysis for industrial quality assurance, funds management for financial teams and automation of processes/operations for warehousing firms/ distributors. It has numerous applications when they are integrated with IOT and blockchain. In any particular supply chain, storage and visibility of data to all the stakeholders helps all members involved to take accurate decisions on a real-time basis, automating systems through sensors, cloud and are measurable. Fuzzy and other analysis methods such as grey system theory can be applied in every process that is measurable and helps to make sensible and predictive decisions.

\section{Supply chain operations challenges}

Supply chain operations include the execution plan of all the processes and connectivity of all the systems (Banerjee, 2015). All companies need to improve their supply chain operations to increase their financial and operational performance. The involvement of a large number of stakeholders in the supply chain increases the operational challenges and reduces the one-toone interaction among different members. There are some challenges in the supply chain because of its complex structure (see Table 2):

In Figure 1, implementation path of blockchain technology in supply chain can be seen. There are four layers in blockchain server such as ledger layer, smart contract layer, transaction layer and data input layer for data acquisition, data processing, data verification

\begin{tabular}{|c|c|c|c|}
\hline $\begin{array}{l}\mathrm{Sr} \\
\mathrm{No}\end{array}$ & Challenge & Description of challenge & Source \\
\hline 1 & $\begin{array}{l}\text { Lack of trust among all } \\
\text { stakeholders }\end{array}$ & $\begin{array}{l}\text { Supply chain contains many stakeholders with a } \\
\text { complex processing chain, so access of all real-time } \\
\text { activities in the operations is major reason of trust } \\
\text { among different stakeholders }\end{array}$ & $\begin{array}{l}\text { Francisco and } \\
\text { Swanson (2018) }\end{array}$ \\
\hline 2 & $\begin{array}{l}\text { Efficiency at each level } \\
\text { cannot be tracked }\end{array}$ & $\begin{array}{l}\text { In supply chain network, there are many operations } \\
\text { like manufacturing, employee and inventory } \\
\text { management, logistics, sales, etc. so tracking the } \\
\text { efficiency of all the operations is difficult without any } \\
\text { common platform }\end{array}$ & $\begin{array}{l}\text { Huo (2012), Zheng } \\
\text { et al. (2018) }\end{array}$ \\
\hline 3 & $\begin{array}{l}\text { Less transparency and } \\
\text { productivity }\end{array}$ & $\begin{array}{l}\text { In large supply chain networks because of more } \\
\text { members involved and many operations, there is less } \\
\text { transparency of all operations to all the stakeholders/ } \\
\text { members }\end{array}$ & Kshetri (2018) \\
\hline 4 & Lack of digitalization & $\begin{array}{l}\text { In traditional supply chain, there is no digital } \\
\text { platform that connects all the supply chain } \\
\text { organizations which enables difficulties like payment } \\
\text { efficiency, transparency, management and control }\end{array}$ & $\begin{array}{l}\text { Panicker et al. } \\
(2016)\end{array}$ \\
\hline 5 & $\begin{array}{l}\text { Lack of integration at all } \\
\text { levels }\end{array}$ & $\begin{array}{l}\text { There should be integration platform that connects } \\
\text { supplier, manufacturer, distributor, retailer and } \\
\text { consumer which helps to ease the operations and } \\
\text { real-time data tracking and securely storing of data }\end{array}$ & Pasi et al. (2020) \\
\hline 6 & $\begin{array}{l}\text { Lack of end-to-end } \\
\text { visibility }\end{array}$ & $\begin{array}{l}\text { Visibility of complete product lifecycle in supply } \\
\text { chain network is very necessary else there might be } \\
\text { many problems such as logistics challenges, delivery } \\
\text { time tracking and consumer trusts }\end{array}$ & $\begin{array}{l}\text { Rane and } \\
\text { Thakker (2019) }\end{array}$ \\
\hline 7 & $\begin{array}{l}\text { Handling and } \\
\text { maintaining legal } \\
\text { contracts }\end{array}$ & $\begin{array}{l}\text { Maintaining all kinds of contracts such as financial } \\
\text { contracts, ownership certificate and investment } \\
\text { contracts physically is difficult. Legal team can face } \\
\text { challenges to send contracts to other stakeholders } \\
\text { securely }\end{array}$ & $\begin{array}{l}\text { Banerjee et al. } \\
(2018)\end{array}$ \\
\hline
\end{tabular}

Table 2.

Supply chain operations challenges 


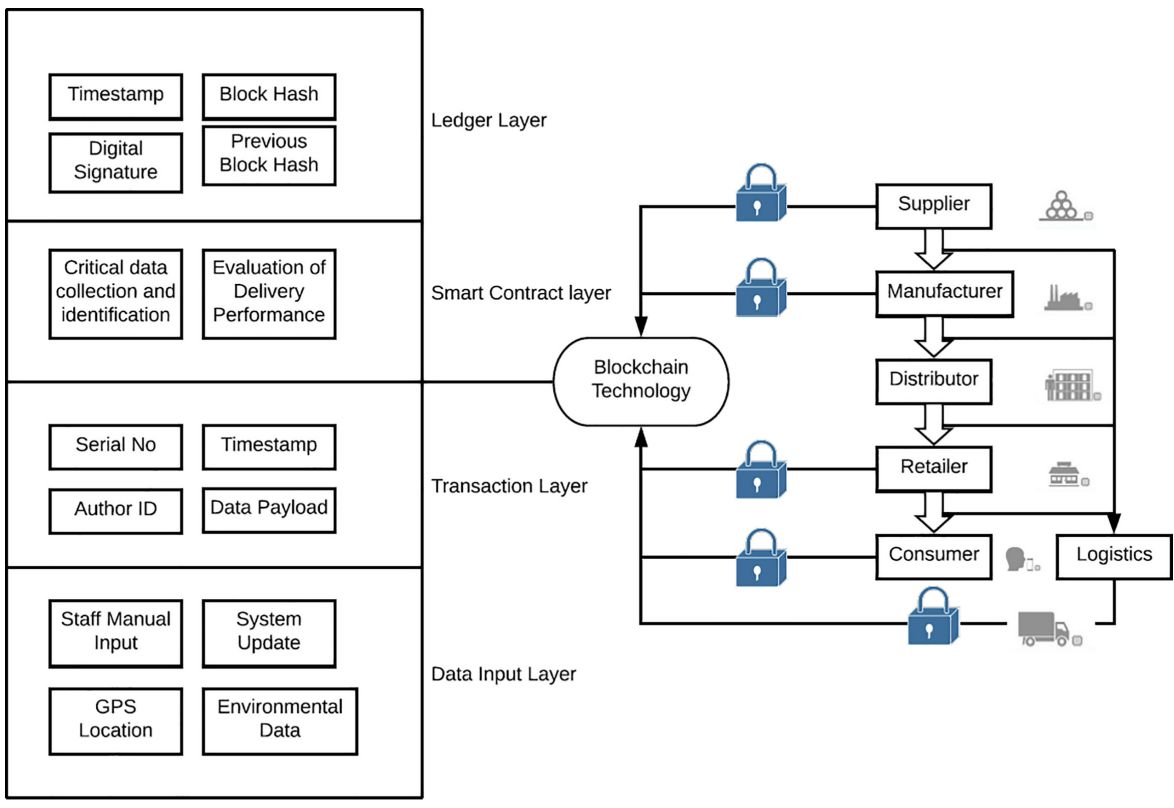

Source(s): Author
Blockchainintegrated technologies

83

Figure 1.

Blockchain technology for supply chain

and data storage. All member/stakeholders involved in supply chain are nodes through which they are connected to a blockchain server.

\section{Blockchain and smart contracts}

A smart contract can verify its correctness, imposed instructions and predefined rules. The smart contracts are self-executing, immutable and distributed. Smart contracts can be programmed with a language named solidity. Smart contracts is storing of contracts which is similar to storing of transactions on blockchain (Rane and Thakker, 2019). Smart contract is the nontampering computer program that is stored inside a blockchain server. They are completed immutable and distributed. Once the smart contract is created and stored on blockchain server, it becomes challenging to tamper with the contract's code. Everyone on the network validates the output. The feature of blockchain smart contracts gives the ability to program the blockchain to govern transactions among participants involved in decision-making or generating and accessing the data (Banerjee et al., 2018).

Smart contracts can self-manage and self-execute payments. They can build function libraries and are good at authenticating. Trust of process executions can be achieved by encoding business operations into smart contracts that impose the correct performance among untrusted parties, and trust of IOT information is derived from the agreement of business partners that mutually select IOT services for each task execution in a business process (Xu and Viriyasitavat, 2019). Smart contracts can compute business logic and understand upto the core they facilitate three functions:
(1) Store rules
(2) Validate rules 
MSCRA

3,2

84
(3) Self-execute rules

Blockchain technology can be used by integrating delivery platforms and payment systems in digital contracts that runs across organizations, integration with logistics providers and other supply chain members. The main feature of blockchain in a smart contract is "trustless" transactions. Smart contract handles enforcement, management, performance and payment. The smart contract is an agreement between two people on the digital network. Smart contract on blockchain reduces time and cost delays of handling and forming the contract manually. The possible cases of smart contracts are pre-contracted budgets and deals to automated access systems and extending from e-commerce to autonomous machine transactions (Sulkowski, 2019). Ujo Music is a decentralized music platform that allows the artists to record a piece of music on a blockchain-based smart contract that shows the amount of share of each stakeholder in the project. Smart contracts and blockchain will revolutionize many industries and businesses to enable electronic transactions without any human intervention (Stefansson, 2002). Smart contract gives the registry of every part of the product on the ledger. It shows the ownership certificate of all the products or components that helps to gain trust among all the supply chain members. Supply chain contains cupplier, manufacturer, distributor, retailer and consumer cycle. There are many stakeholders involved in the complete process. Once the retailer or the manufacturer receives a product, they can check the originality of every component of the product. The supplier might sometime do fraud and send the duplicate part to a manufacturer that decreases quality of the product and also the life of product. If the consumer gets a complaint about the product, the retailer can directly check which supplier has done the fraud and directly report to him due to smart contracts. All the investment contracts of an organization such as term sheet, funding agreements, partnership documents, manufacturer documents and organization collaboration documents can be directly stored on blockchain server in the form of smart contracts. Such important documents are encrypted and available to other stakeholders through blockchain in a secured way. Traditional method of handling and maintaining all types of contracts physically can be easily solved through integration of blockchain and smart contract (Reyna et al., 2018). Digital and self-executing smart contracts helps organization for their cost cutting in legal team. Some organization can save their employee salary that is responsible for renew and verification of legal contracts, tax audits and compliances alert. Blockchain and smart contract if used properly can help companies to save their legal fines, deductions for late payment of taxes and reduce counterfeiting and frauds.

The applications of blockchain and smart contracts in supply chain are:

(1) Protecting copyrighted content (Savelyev, 2018).

(2) Store employee and land contracts

(3) Store stakeholder and investments contracts

(4) Ownership and registry of all assets or products

(5) Peer-to-peer transactions

In Figure 2, all supply chain members are connected on a common blockchain server where all the smart contracts can be saved. Supply chain members/stakeholders can access to all smart contracts and verify updating of contracts through mobile application and consumers can get the access through bar code. There are bar codes on all manufactured products so that anyone can get the access of ownership, verification details and proof of origin. All the deals and contracts involved in the companies are stored on server and are encrypted so that all allowed members and organization can access all contracts on real-time. 


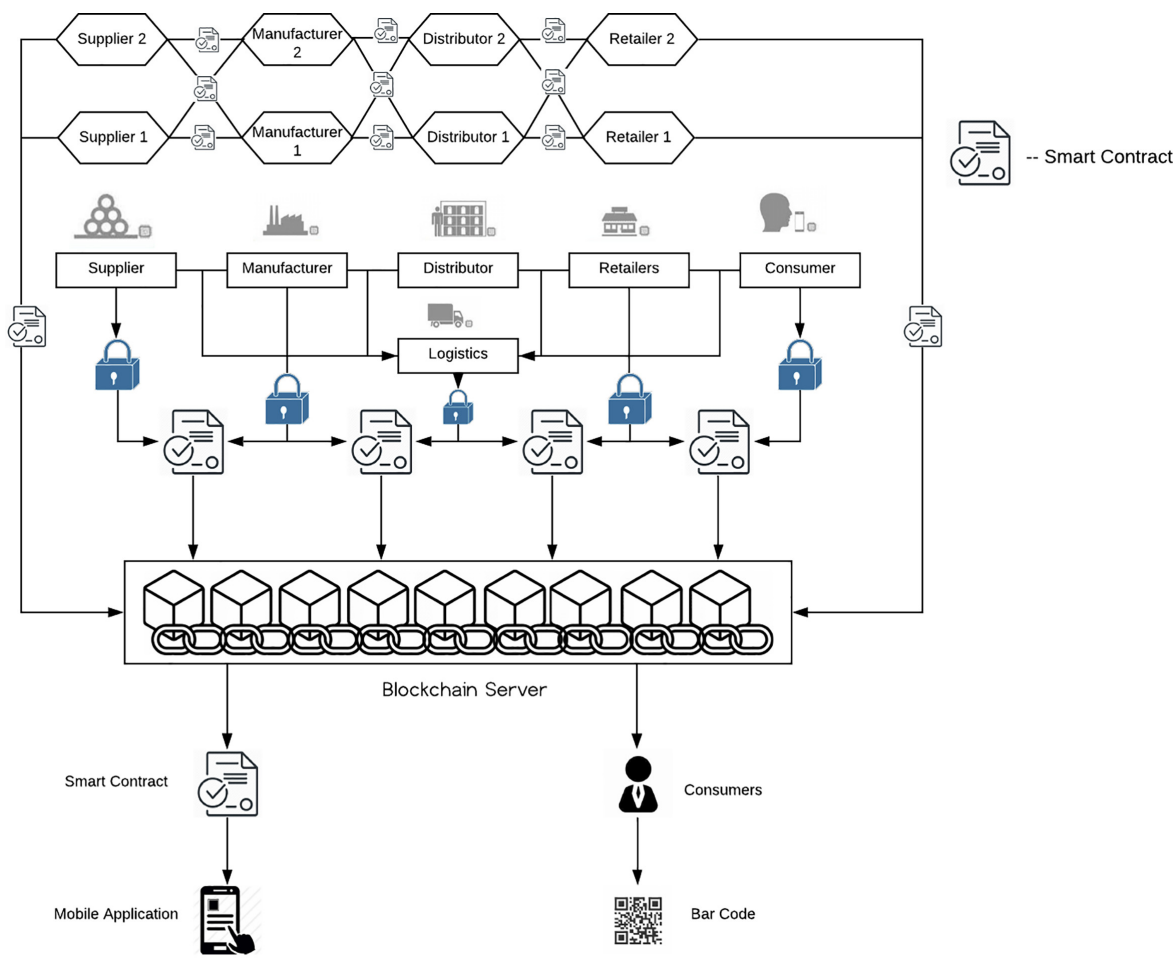

Blockchainintegrated technologies

85

Source(s): Author

\section{Technologies for integration with blockchain}

The technologies that can be integrated with blockchain technology to turn supply chain operations more flexible and agile are IOT and AI. Both the technologies are separately used in industries and not many organizations have incorporated blockchain along with these technologies. Following sub-sections discus integration of IOT and AI with blockchain network and information flow for the same.

\subsection{Blockchain and IOT}

IOT refers to the IOT that takes data from the server and stores on the Internet, which can be examined by the admin anytime and anywhere (Alaba et al., 2017). The digital supply chain (DSC) is the best example representing the integration of blockchain and IOT. The DSC requires the dynamic collaboration of partners by integrating or exchanging specific data across various organizations and systems (Viriyasitavat et al, 2019). At each step and every process location of packages, containers and products can be tracked through IOT system integrated with RFID tags, GPS tag, sensors, bar code and chips. This allows an enhanced, real-time tracking of goods from their origins. Blockchain has genuine potential to gain data security and trust for automation and intelligence development in IOT (Xu and Viriyasitavat, 2019). IOT works in the supply chain through these four necessary steps:
(1) Sensors and actuators
(2) Internet gateways 
MSCRA

3,2

86
(3) Edge IT analytics

(4) Data center management

The sensors are connected to machinery to automate some processes and gain real-time data. Those sensors are connected to Internet gateways of that particular area. The Internet gateways take real-time data through sensors that are stored in the database. Decision analytics is done with that data for the decision-making process (Novo, 2018). As it is real-time data, it helps to make right and genuine decisions for the further process. The real-time data through Internet-based medium increase efficiency and productivity of the supply chain. Integration of blockchain and IOT increases the trust among all the stakeholders and members involved in the complete supply chain because they get access to the real-time data. Everyone in the chain can track the stage of the product and assume the delivery time. This integration helps in the inventory management, demand forecasting, financial and operational management of all the individual organizations involved in the chain. Asset tracking is the most crucial feature of blockchain-IOT in supply chain. All the logistics providers' activities can be tracked entirely with the help of IOT, and it is accessible to all the members of the chain with the help of a decentralized blockchain server (Pureswaran, 2015). This access of logistics provider helps all the members of the string to manage their operations efficiently (Hackius and Petersen, 2017). The distributor has the most advantage of blockchain-IOT integration as he can track all the goods in the large warehouse through RFID tags (Angeles, 2009). It helps to increase the trust of all the members that all the rights are safe in the warehouse. Feedback of products shared by customers by using smartphones can directly be transferred to the manufacturer, which allows companies to given efficient customer services. These IOT characteristics bring about a trust concern for the utilization of IOT services in modern business processes (Xu and Viriyasitavat, 2019). The integration of blockchain and IOT also helps to solve problems related to fragmented data sources. Blockchain technology provides strong security to IOT data and devices and predictive analysis and legal contracts as they are vulnerable by $51 \%$ of attack on connected servers (Alphand et al., 2018). Blockchain-IOT integration in supply chain helps supply chain members to reduce their employees responsible for traditional supply chain management and save their large amount of revenue. Manufacturers can reduce staff of quality assurance and maintenance team as that task can be efficiently done by sensors on the machinery, and real-time data are uploaded through IOT on blockchain server. The allotted supervisor can keep track of all the production through server and change the required setting as per reports and data on blockchain server. It is very important for any organization to make a good KPI (key performance indicator) to increase efficiency of processes; blockchain-IOT can help companies to boost their KPI system on real-time basis which is visible to all stakeholders.

RFID and barcodes are how the products or goods are tracked, and they help manage the inventory efficiently (Kim and Garrison, 2010). RFID tag passes the data to the RFID reader, which is connected to the Internet. Transportation products are fitted with the tracking device, which provides real-time information of goods along the supply chain. From manufacturing equipment, maintenance, production efficiency and shipping notices through logistics service provider and RFID scanning, everything is tracked on computerized systems (Fan et al., 2015). The integration of blockchain and IOT helps to improve the existing traditional supply chain operations and transform it into a new supply chain to increase operations efficiency and productivity (Xu and Viriyasitavat, 2019). Identifying product damage with the help of sensors and ML (machine learning) is a critical application. The data are uploaded on the blockchain server, and the supervisor responsible for that task can do the required settings. The uses of blockchain and IOT in supply chain are: 
(1) Real-time data of product to all the stakeholders

(2) Tracking of stages of product

(3) Better visibility into procurement.

Blockchainintegrated technologies

(4) Reliable data analytics for decision-making

(5) Improvement in operational and financial performance of all members in the chain

(6) Identifying product damage

In manufacturing supply chain, blockchain and IOT integration can be the new revolution because of its numerous advantages such as real-time data, efficient operations, secured storage of data on real-time basis, etc. (Kehoe and Boughton, 2001). The major operations in which blockchain and IOT integration can help are: production planning and control, supply chain real-time data of raw material, equipment, machinery maintenance, quality assurance, inventory management of manufactured goods, etc. (Fang et al., 2016). Efficient resource utilization can be done with the help of this integration due to real-time data regularly.

In Figure 3, blockchain and IOT integration roadmap and benefits in supply chain is displayed. Sensors and other data sources are connected to all members individually and uploaded on Internet gateways and associated cloud platforms. After processing data, data management and storage systems help organizations in data segmentation through data analysis and create proper business reports (Haddud et al., 2017). Such reports are very accurate and help organization to increase their revenue, create new business models and work on development in required field. All real-time reports are uploaded on the blockchain server that is visible and accessible to other members/stakeholders which helps them in planning and strategizing their operations.

\subsection{Blockchain and AI (artificial intelligence)}

$\mathrm{AI}$ is used to create intelligent computers and machines that act like humans. AI algorithms are developed to make calculated and real-time data-analyzed decisions. John McCarthy explained term, "Artificial Intelligence" as a way to get the machine doing things that is usually performed by human intelligence (Shubhendu and Vijay, 2013). Both AI and blockchain technology can help the supply chain increase the security of data storage, double the efficiency of data and make smart decisions (Banerjee et al., 2018). Blockchain stores a large amount of data securely, and AI creates newer scenarios and discovers patterns based on data behavior.

As supply chain includes many stakeholders and managers, there is large amount of data processed on the blockchain network (Chen, 2018). The integration of blockchain and $\mathrm{AI}$ in the supply chain helps analyze a large amount of data and make better decisions. Decisions taken by AI can be more accurate than individual choices because of the large amount of data. Solutions are being developed by the researchers in specific industries that could revolutionize way of storing data, its analysis and especially for the supply chain and manufacturing industry. IBM has entered the AI-blockchain-based management with supply chain suite. To date, the majority of deep learning methods and machine learning of AI depend on centralized model for training in which a group of servers run a specific model against training and validating datasets (Salah et al., 2019). With access to an identical view of a shared, trusted and secured platform of transactions, data, analytics and documents helps in supply chain to take calculated decisions in all parts of operations. Integration of AI and blockchain helps to enhance data security, which allows all the manufacturers to gain trust over all the raw material and components provided by the supplier through digital 
MSCRA

3,2

88

Figure 3.

Blockchain technology and IOT integration for supply chain

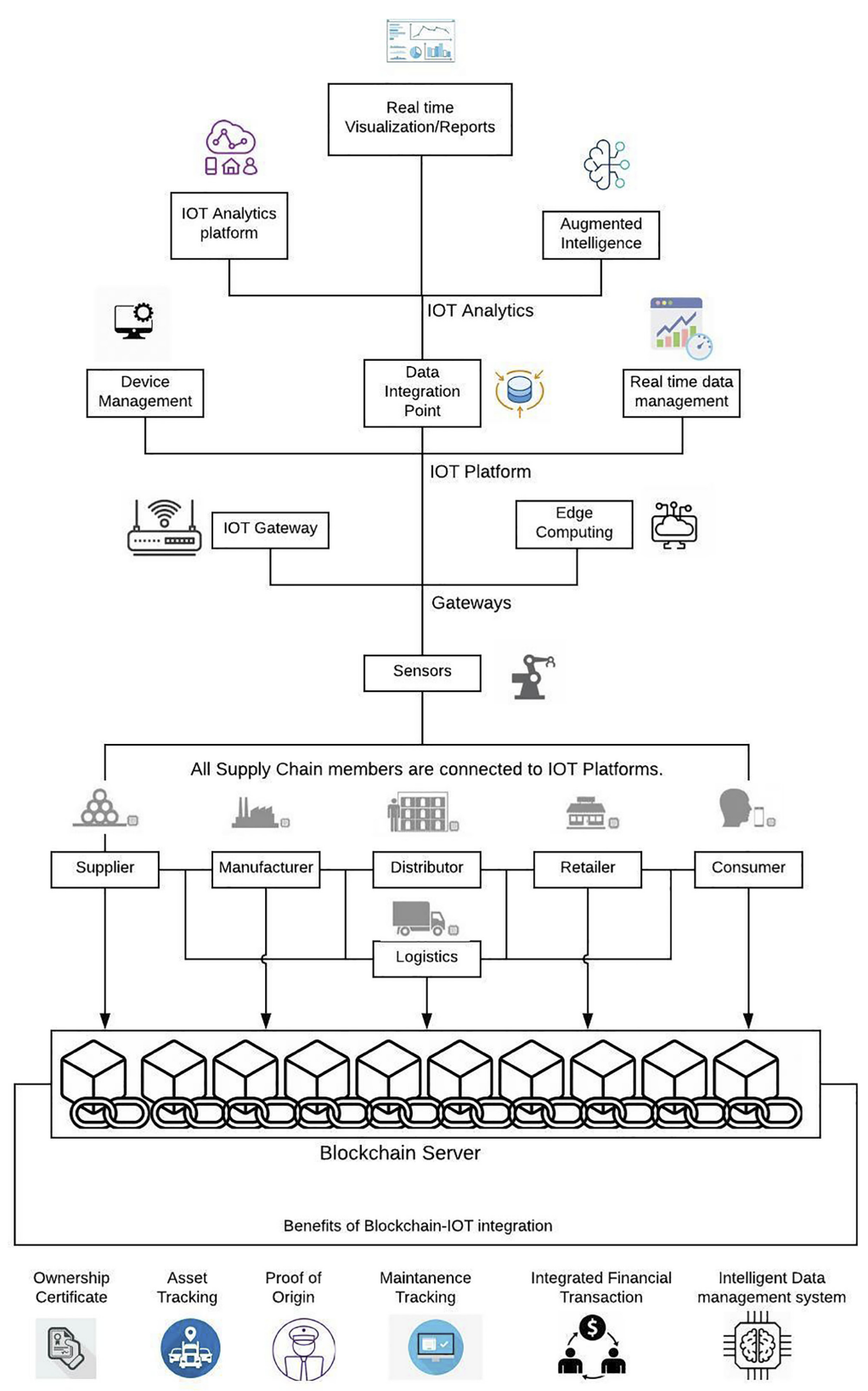

Source(s): Author

signature with a private key. Recording an AI system's decision-making process on a blockchain would increase transparency and gain public trust to understand the robotic decisions (Salah et al., 2019). The integration of AI and blockchain technologies enables 
intelligent Decentralized Autonomous Agents (or DAOs) for automatic and fast validation of data/value/asset transfers among different stakeholders in a supply chain (Magazzeni et al., 2017). Applying AI techniques to blockchain-based business transactions can help refine the supply chain by automating the entire process. AI-enabled NLP scans through the supply chain documents like contracts, purchase orders, chat logs with customers or suppliers and significant others to identify commonalities that are used as feedback to optimize SCM as part of continual improvement. Decentralized AI algorithms and applications can be developed by blockchain-AI integration in real world.

When AI platforms and technology are integrated with blockchain, can identify data patterns and predictive analysis which includes predicting future demand, capture data from the point of sale systems, old purchase information, predicting sales patterns, identifying potential issues in advance, optimizing routes to reach the destination and handling network traffic in the overall supply chain (Salah et al., 2019). It also helps in inventory management data and demand forecasting to give the alert about the stock clearance. It can help notify the correct time to order the new stock by analyzing all the previous data processed through all the supply chain members on the blockchain server. Manufacturers reduce supply chain latency for components and parts used in their most heavily customized products using machine learning algorithms connected to the AI, and blockchain play a significant role in the finance sector of the supply chain as all the transactions are processed and stored on the blockchain server by all the stakeholders involved in the supply supply chain (Pfohl and Gomm, 2009). AI helps to manage all the operations and, through its data analysis algorithm, supports all the stakeholders to keep track of expenses, the financial performance of the company existing in its supply chain. This integration analyses all the transactions according to the organization involved in the supply chain and helps notify about the requirements of funds and plans to raise funds for upcoming operational expenses. Intelligent data-driven decisions help all the stakeholders and members of the supply to make correct decisions on a real-time basis (Zhao et al., 2016). Applying AI algorithms to the blockchain-based transactions can help to reframe supply chain by automating the entire process and finding new revenue sources. AI agents and IOT devices helps supplier, manufacturer, logistics provider and distributor to improve the supply chain operations with predictive analysis that allows monitoring all the requirement of all the members involved in the supply chain. AI algorithm and blockchain integration reduces the work of supply chain managers of the organization and increases their efficiency. Planning strategies help in operational efficiency and resilience of AI applications and systems by taking the current input state and executing different logic and rule-based algorithms to reach predefined goals (Contreras-Cruz et al., 2017). This integration of blockchain and AI can also be used in the banking sector to store all the data securely on blockchain server and data analysis, decisions of approving loans, managing cash flow and deciding customer's withdraw limit depending on his previous data and transactions through AI.

In manufacturing supply chain, AI driven smart contracts can increase the effectiveness of regular smart contract through analysis. AI can analyze past contracts and suggest changes for future contracts. Predictive maintenance is the most important advantage of blockchain-AI integration. AI algorithm installed in a machine can reduce the maintenance uncertainties in the machine and improve the production quality efficiency due to standard outputs.

In Figure 4, in blockchain and AI integration, once the data are acquired through all supply chain members and data sources, all the data are properly processed and segmented through normalizing, encoding and transformation. The data that are not required is removed from the dataset. The segmented dataset is then trained as per the execution and report requirements. Then an AI algorithm is imposed on the

Blockchainintegrated technologies 
MSCRA

3,2

90

Figure 4.

Blockchain technology

and $\mathrm{AI}$ (artificial

intelligence)

integration for

supply chain

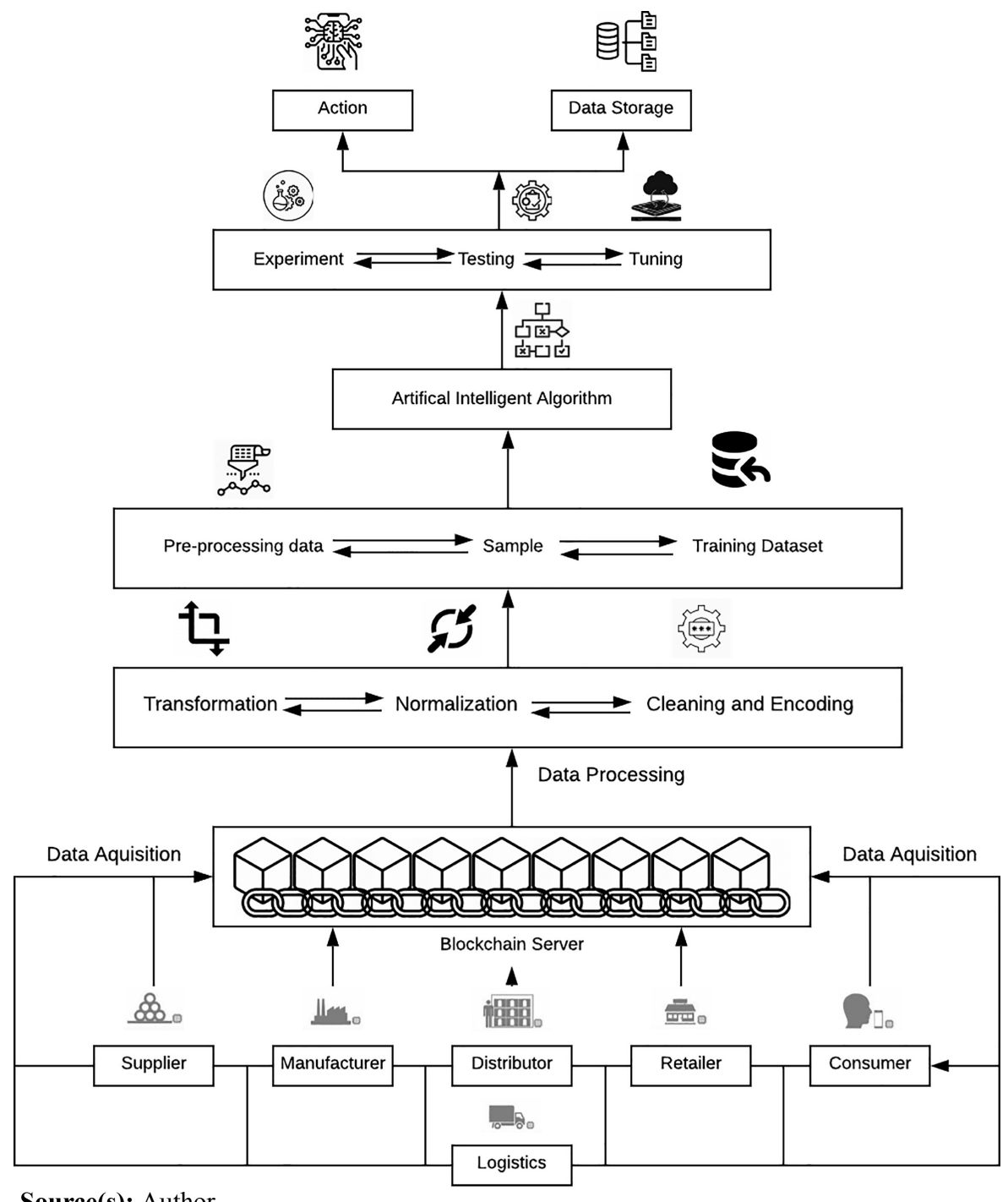

Source(s): Author

dataset, and the data are then experimented, trained for a particular output. The output that is concluded is compared with the real-time data and reports and a necessary action is taken. Model recalibration takes place if the results are not as per required output.

\section{Solutions for supply chain challenges}

Solutions for supply chain challenges is shown in Table 3. 


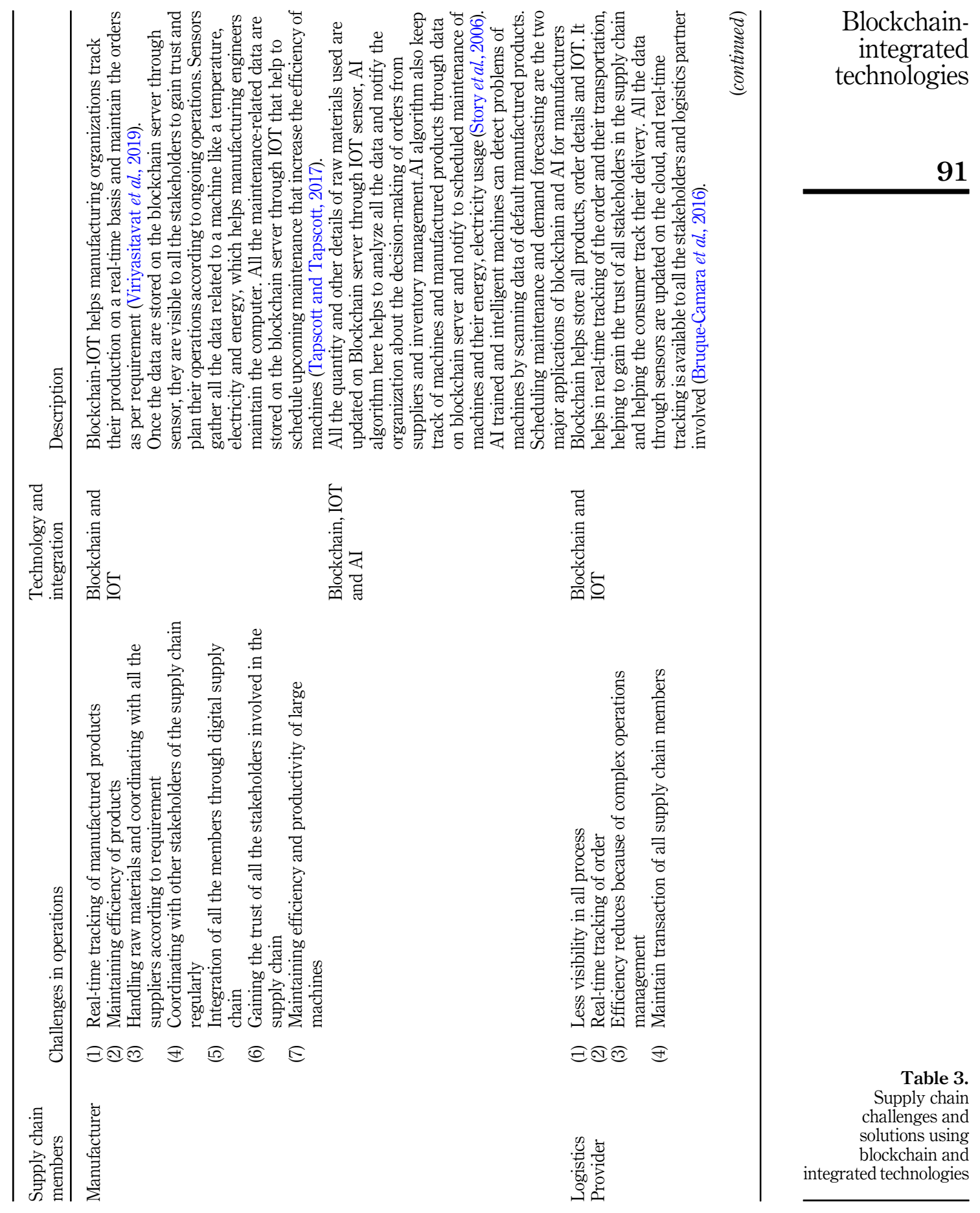


MSCRA

3,2

92

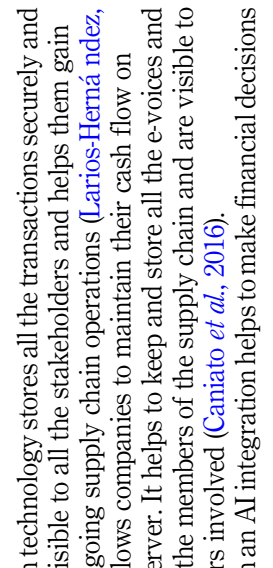

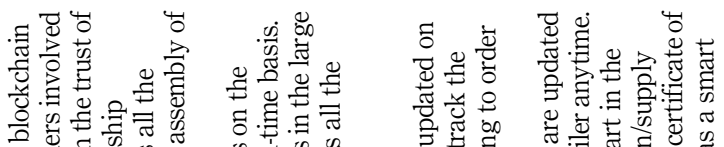

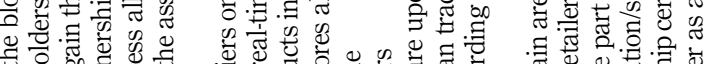

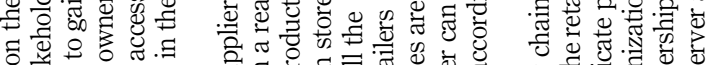

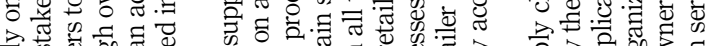

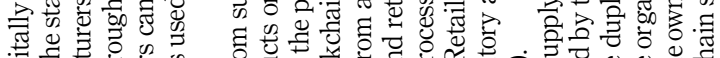

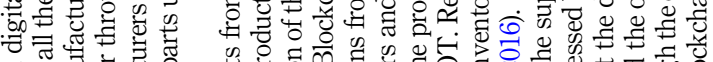

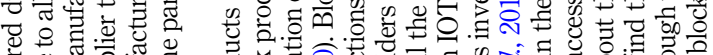

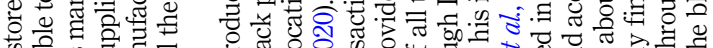

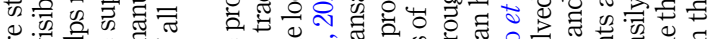

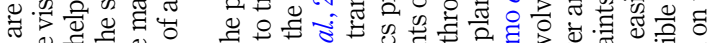

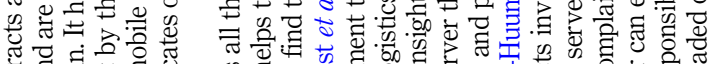

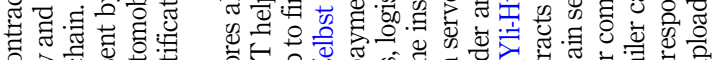

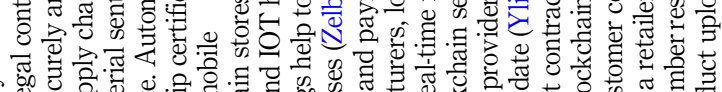

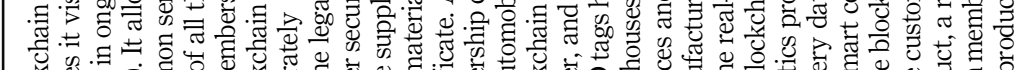

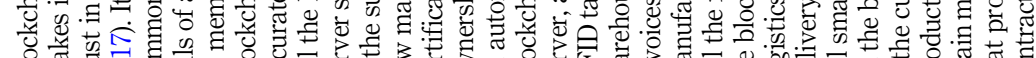

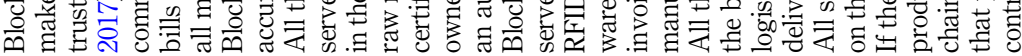

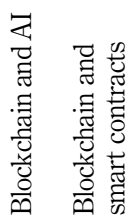

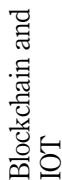

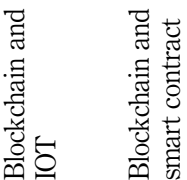

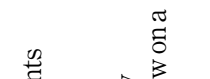

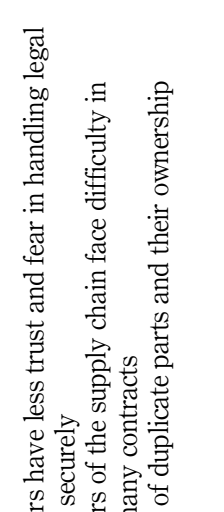

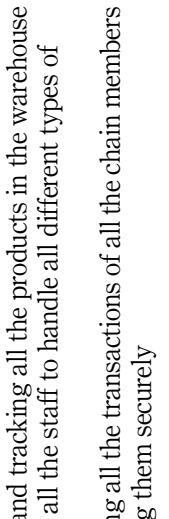

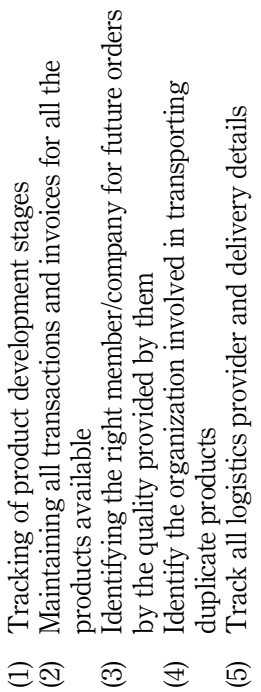

Table 3.
的

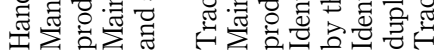

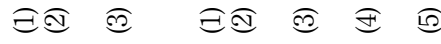

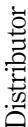

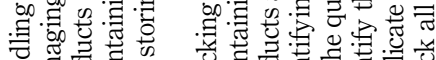




\section{Discussion}

Adopting all modern technology such as integration of blockchain with IOT, AI can increase the efficiency of operations, employees and organizations. It also brings many responsibilities and guidelines to be followed by the organization and all the supply chain participants. Some of the guidelines that need to be followed by the members of supply chain in their organization are:

(1) All the companies have different operational strategies with a unique way of tracking operations and executing the tasks. It is advised to research all the company processes first and then make an implementation plan to get the most benefit of technology in their supply chain operations.

(2) Supply chain involves many members involved from the organization and outside the organization, so before adopting any technology, it is essential to make a proper flow of the technology usage, which involves and benefits all the members in the supply chain.

(3) Adopting new modern technology in traditional supply chain is highly expensive, so a proper financial plan is preferred, and accurate unit economics should be ready before selecting any technology implementation in the organization. A company needs to plan for long term in terms of investment in technology and its returns.

(4) All the technologies mentioned above that enhance the flexibility and agility of supply chain operations are very modern and challenging to learn by old employees. All companies have to plan training sessions and workshops for the employees, laborers, managers and stakeholders involved in the operations to make them efficient and smooth use of the technology.

(5) The organizations, members involved in supply chain have to evaluate all the legal documents and legal compliance requirements to adopt new technology. There could be much legality in smart contracts, blockchain servers and IOT laws, as data are the base of all these technologies.

\section{Conclusion, recommendations and implications}

This paper presents the findings and research in the blockchain technology that can be used in the supply chain to increase efficiency and enhance the agility of the supply chain. The challenges faced by industries in the traditional supply chain discussed, and to overcome the difficulties, blockchain technology and its integration with other modern technologies are considered for implementation. Based on the literature surveys and survey from a few industry experts, challenges and their specific solution are identified in the chart in integration with the blockchain technology. Blockchain technology can become one of the essential techniques in supply chain operations in the future. The architecture developed for blockchain technology for the supply chain and its integration with the supply chain helps overcome some of the challenges analyzed in this research. Blockchain technology and its integration with smart contracts, IOT and AI, when used in the traditional supply chain, can not only solve the challenges but also bring new revenue sources and improve the business model financially and operationally. This architecture can be roadmap for organizations planning to implement blockchain technology in their supply chain and convert traditional supply chain into a fully digital supply chain. The architecture demonstrates the application of blockchain technology and its integration with modern technologies such as smart contracts, IOT, AI for all the operations involved in the supply chain. Adopting these technologies helps improve services and develop legal, finance, employee management and trust among stakeholders.
Blockchain-
integrated
technologies

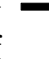


MSCRA

3,2

94

Supply chain operations face many challenges in spite of the availability of advanced technologies. The major challenges for the supply chain operations are time, consistency, transparency and trust among all stakeholders. Even if blockchain technology and its integration with AI and IOT are advanced technologies to solve barriers, organizations might not be ready to share information on a platform for all parties to view and access. The government regulations vary in all the countries across the world, so international procurement standards are different for all the supply chain partners from different countries. Standard operating procedures are required to be developed in all the supply chain activities, processes and operations for successful implementation of these technologies in supply chain network. Small organizations and companies on a small scale with less revenue might face problems in adopting this technology because of less technical knowledge and expense. The company's objectives, resources and employees need to align all their activities with the digital supply chain revolution.

\section{References}

Abeyratne, S.A. and Monfared, R.P. (2016), "Blockchain ready manufacturing supply chain using distributed ledger", International Journal of Renewable Energy Technology, Vol. 5, pp. 1-10.

Alaba, F., Othman, M., Hashem, I. and Alotaibi, F. (2017), "Internet of Things security: a survey", Journal of Network and Computer Applications, Vol. 88 No. C, pp. 10-28.

Alphand, O., Amoretti, M., Claeys, T., Dall 'asta, S., Duda, A., Ferrari, G. and Dall'asta, S. (2018), "IOT chain: a blockchain security architecture for the internet of things", IEEE Wireless Communications and Networking Conference (WCNC), pp. 1-6.

Angeles, R. (2009), "Anticipated IT infrastructure and supply chain integration capabilities for RFID and their associated deployment outcomes", International Journal of Information Management, Vol. 29 No. 3, pp. 219-231.

Banerjee, A. (2015), "Information technology enabled process re-engineering for supply chain leagility", International Journal of Information Technology and Management, Vol. 14 No. 1, pp. 60-75.

Banerjee, M., Lee, J. and Choo, K.K.R. (2018), "A blockchain future for internet of things security: a position paper", Digital Communications and Networks, Vol. 4 No. 3, pp. 149-160.

Bi, R., Davison, R.M., Kam, B. and Smyrnois, K.X. (2013), "Developing organizational agility through IT and supply chain capability", Journal of Global Information Management, Vol. 21 No. 4, pp. 38-55.

Bruque-Camara, S., Moyano-Fuentes, J. and Maqueira-Marin, J.M. (2016), "Supply chain integration through community cloud: effects on operational performance", Journal of Purchasing and Supply Management, Vol. 22 No. 2, pp. 141-153.

Caniato, F., Gelsomino, L.M., Perego, A. and Ronchi, S. (2016), "Does finance solve the supply chain financing problem?”, Supply Chain Management, Vol. 21 No. 5, pp. 534-549.

Chen, R.Y. (2018), "A traceability chain algorithm for artificial neural networks using T-S fuzzy cognitive maps in blockchain”, Future Generation Computer Systems, Vol. 80, pp. 198-210.

Cole, R., Stevenson, M. and Aitken, J. (2019), "Blockchain technology: implications for operations and supply chain management”, Supply Chain Management: International Journal, Vol. 24 No. 4, pp. 469-483.

Contreras-Cruz, M.A., Lopez-Perez, J.J. and Ayala-Ramirez, V. (2017), "Distributed path planning for multi-robot teams based on arti_cialbee colony", Proceedings of IEEE Congress Evolutionary Computation (CEC), pp. 541-548.

Fan, T., Tao, F., Deng, S. and Li, S. (2015), "Impact of RFID technology on supply chain decisions with inventory inaccuracies", International Journal of Production Economics, Vol. 159 No. 2015, pp. 117-125. 
Fang, C., Liu, X., Pardalos, P.M. and Pei, J. (2016), "Optimization for a three-stage production system in the Internet of Things: procurement, production and product recovery, and acquisition", International Journal of Advanced Manufacturing Technology, Vol. 83 Nos 5/8, pp. 689-710.

Francisco, K. and Swanson, D. (2018), "The supply chain has no clothes: technology adoption of blockchain for supply chain transparency", Logistics, Vol. 2 No. 1, p. 2.

Hackius, N. and Petersen, M. (2017), "Blockchain in logistics and supply chain: trick or treat?", Reinforced Plastics, Vol. 9783745043 April, p. 23.

Haddud, A., DeSouza, A., Khare, A. and Lee, H. (2017), "Examining potential benefits and challenges associated with the Internet of Things integration in supply chains", Journal of Manufacturing Technology Management, Vol. 28 No. 8, pp. 1055-1085.

Hu, W., Hu, Y.W., Yao, W.H., Lu, W.Q., Li, H.H. and Lv, Z.W. (2019), "A blockchain-based smart contract trading mechanism for energy power supply and demand network", Advances in Production Engineering And Management, Vol. 14, pp. 284-296.

Huo, B. (2012), "The impact of supply chain integration on company performance: an organizational capability perspective", Supply Chain Management: an International Journal, Vol. 17 No. 6, pp. 596-610.

Kehoe, D. and Boughton, N. (2001), "Internet-based supply chain management: a classification of approaches to manufacturing planning and control", International Journal of Operations and Production Management, Vol. 21 No. 4, pp. 51-525.

Kim, S. and Garrison, G. (2010), "Understanding users' behaviors regarding supply chain technology: Determinants impacting the adoption and implementation of RFID technology in South Korea", International Journal of Information Management, Vol. 30 No. 5, pp. 388-398.

Kim, H.M. and Laskowski, M. (2018), "Toward an ontology-driven blockchain design for supply-chain provenance", Intelligent Systems in Accounting, Finance and Management, Vol. 25 No. 1, pp. 18-27.

Kshetri, N. (2018), "1 Blockchain's roles in meeting key supply chain management objectives", International Journal of Information Management, Elsevier, Vol. 39, pp. 80-89.

Larios-Hernández, G.J. (2017), "Blockchain entrepreneurship opportunity in the practices of the unbanked”, Business Horizons, Vol. 60 No. 6, pp. 865-874.

Li, X., Jiang, P., Chen, T., Luo, X. and Wen, Q. (2020), "A survey on the security of blockchain systems”, Future Generation Computer Systems, Vol. 107, pp. 841-853.

Magazzeni, D., McBurney, P. and Nash, W. (2017), "Validation and verification of smart contracts: a research agenda", Computer, Vol. 50 No. 9, pp. 50-57.

Nawari, N.O. and Ravindran, S. (2019), "Blockchain technology and BIM process: review and potential applications", Journal of Information Technology in Construction, Vol. 24, pp. 209-238.

Novo, O. (2018), "Blockchain meets IOT: an architecture for scalable access management in IOT", IEEE Internet of Things Journal, Vol. 5 No. 2, pp. 1184-1195.

Panicker, S., Patil, V. and Kulkarni, D. (2016), "An overview of blockchain architecture and it's applications", International Journal of Innovative Research in Science, Engineering and Technology, Vol. 3297 No. 11, pp. 1111-1125.

Pasi, B.N., Mahajan, S.K. and Rane, S.B. (2020), Smart Supply Chain Management: A Perspective of Industry 4.0, Vol. 29 No. 5, pp. 3016-3030.

Pfohl, H.-C. and Gomm, M. (2009), "Supply chain finance: optimizing financial flows in supply chains", Logistics Research, Vol. 1 Nos 3-4, pp. 149-161.

Pureswaran, V. (2015), "Empowering the edge-practical insights on a decentralized Internet of Things", IBM Institute for Business Value.

Rane, S. and Thakker, S. (2019), "Green procurement process model based on blockchain-IOT integrated architecture for a sustainable business", Management of Environmental Quality: An International Journal, Vol. 31 No. 3, pp. 741-763.
Blockchainintegrated technologies 
MSCRA

3,2

96

Rane, S. and Narvel, Y.A.M. (2019), "Re-Designing the business organisation using disruptive innovations based on Blockchain-loT integrated architecture for improving agility in future industry 4.0”, Benchmarking: An International Journal, doi: BIJ-12-2018-0445.

Reyna, A., Martín, C., Chen, J., Soler, E. and Díaz, M. (2018), "On blockchain and its integration with IOT. Challenges and opportunities”, Future Generation Computer Systems, Vol. 88, pp. 173-190.

Salah, K., Rehman, M.H.U., Nizamuddin, N. and Al-Fuqaha, A. (2019), "Blockchain for AI: review and open research challenges", IEEE Access, Vol. 7, pp. 10127-10149.

Savelyev, A. (2018), "Copyright in the blockchain era: Promises and challenges”, Computer Law and Security Review, Vol. 34 No. 3, pp. 550-561.

Shireesh, A. and Petrovsky, N. (2016), "Will blockchain technology revolutionize excipient supply chain management?", The Journal of Excipients and Food Chemicals, Vol. 7 No. 3, pp. 76-78.

Shubhendu, S. and Vijay, J. (2013), "Applicability of artificial intelligence in different fields of life", International Journal of Scientific Engineering and Research (IJSER), ISSN (Online), Vol. 1 No. 1, September 2013, pp. 2347-3878.

Stefansson, G. (2002), "Business-to-business data sharing: a source for integration of supply chains", International Journal of Production Economics, Vol. 75 No. 1, pp. 135-146.

Stevenson, M. and Spring, M. (2007), "Flexibility from a supply chain perspective: definition and review", International Journal of Operations and Production Management, Vol. 27 No. 7, pp. 685-713.

Storey, J., Emberson, C., Godsell, J. and Harrison, A. (2006), "Supply chain management: theory,practice and future challenges", International Journal of Operations and Production Management, Vol. 26, pp. 754-774.

Sulkowski, A.J. (2019), "Blockchain, business supply chains, sustainability, and law: the future of governance, legal frameworks, and lawyers?”, Delaware Journal of Corporate Law, Vol. 43 No. 2, pp. 303-345.

Tapscott, D. and Tapscott, A. (2017), "How blockchain will change organizations", MIT Sloan Management Review, Vol. 58 No. 2, pp. 10-13.

Vanpoucke, E., Boyer, K.K. and Vereecke, A. (2009), "Supply chain information flow strategies:an empirical taxonomy", International Journal of Operations and Production Management, Vol. 29 No. 12, pp. 1213-1241.

Viriyasitavat, W., Anuphaptrirong, T. and Hoonsopon, D. (2019), "When blockchain meets Internet of Things: characteristics, challenges, and business opportunities", Journal of Industrial Information Integration, Elsevier B.V.

Viriyasitavat, W., Da Xu, L., Bi, Z. and Sapsomboon, A. (2019), "New blockchain-based architecture for service interoperations in internet of things", IEEE Transactions on Computational Social Systems, Vol. 6 No. 4, pp. 739-748.

Viriyasitavat, W., Xu, L.D., Bi, Z. and Hoonsopon, D. (2019), "Blockchain technology for applications in internet of things - mapping from system design perspective", IEEE Internet of Things Journal, Vol. 6 No. 5, pp. 8155-8168.

Viriyasitavat, W., Xu, L.D., Bi, Z. and Pungpapong, V. (2019), "Blockchain and internet of things for modern business process in digital Economy - the state of the Art", IEEE Transactions on Computational Social Systems, Vol. 6 No. 6, pp. 1420-1432.

Wang, J., Wu, P., Wang, X. and Shou, W. (2017), "The outlook of blockchain technology for construction engineering management”, Frontiers of Engineering Management, Vol. 4 No. 1, p. 67.

Xu, L.D. and Viriyasitavat, W. (2019), "Application of blockchain in collaborative internet-of-things services”, IEEE Transactions on Computational Social Systems, Vol. 6 No. 6, pp. 1295-1305.

Yli-Huumo, J., Ko, D., Choi, S., Park, S. and Smolander, K. (2016), "Where is CurrentResearch on blockchain technology?-a systematic review”, PloS One, Vol. 11 No. 10, e0163477. 
Zelbst, P.J., Green, K.W., Sower, V.E. and Bond, P.L. (2020), "The impact of RFID, IIOT, and Blockchain technologies on supply chain transparency", Journal of Manufacturing Technology Management, Vol. 31 No. 3, pp. 441-457.

Zhao, J.L., Fan, S. and Yan, J. (2016), "Overview of business innovations and research opportunities in blockchain and introduction to the special issue", Financial Innovation, Vol. 2, p. 28, doi: 10. 1186/s40854-016-0049-2.

Zheng, Z., Xie, S., Dai, H.N., Chen, X. and Wang, H. (2018), "Blockchain challenges and opportunities: a survey", International Journal of Web and Grid Services, Vol. 14 No. 4, pp. 352-375.

\section{About the authors}

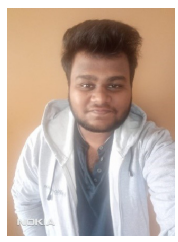

Dhruman Gohil is a Mechanical engineering student at KJSCE interested to do research in Digital Supply chain, advance manufacturing and industry 4.0 revolution. He is founder of Nurturing Lives (NGO) that was started in the first year of engineering. He has interests in entrepreneurship and has expertise in business planning and strategies. He has worked with college professor and developed a Blockchain-IOT integration architecture in manufacturing supply chain with purpose of human intervention. He has successfully completed series of courses on Digital manufacturing from State University of New York.

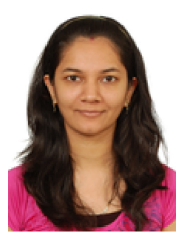

Prof. Shivangi Viral Thakker is working as Assistant Professor in KJ Somaiya College of Engineering, Mumbai and is a Doctoral Student in the Department of Mechanical Engineering, SPCE, Mumbai, India. Her current areas of research are Green procurement, Green supply chain management and artificial intelligence. She is a CII Certified Supply Chain Executive. She has publications in International Journals and Conferences and have received research grant from Mumbai University for her research work. She has completed Master's Degree in Mechanical Engineering. Shivangi Viral Thakker is the corresponding author and can be contacted at: shivangiruparel@somaiya.edu

\section{Blockchain- integrated technologies}

For instructions on how to order reprints of this article, please visit our website:

www.emeraldgrouppublishing.com/licensing/reprints.htm

Or contact us for further details: permissions@emeraldinsight.com 